\title{
Exigência de metionina + cistina para codornas de corte durante a fase de crescimento
}

[Methionine + cystine requirement for European quail during the growing phase]

\author{
F. Ferreira', G.S.S. Corrêa ${ }^{2,6^{*}}$, A.B. Corrêa $a^{3}$, M.A. Silva ${ }^{3,7}$,V.P.S. Felipe ${ }^{1}$, R.R. Wenceslau ${ }^{1}$, \\ L.S. Freitas ${ }^{1}$, R.M. Godinho ${ }^{4}$, N.J.L. Dionello ${ }^{5}$ \\ ${ }^{1}$ Aluno de pós-graduação - Escola de Veterinária - Universidade Federal de Minas Gerais - Belo Horizonte, MG \\ 2Universidade Federal de Mato Grosso - FAMEV - Cuiabá, MT \\ ${ }^{3}$ Escola de Veterinária - Universidade Federal de Minas Gerais - Belo Horizonte, MG \\ ${ }^{4}$ Aluno de graduação - Escola de Veterinária - Universidade Federal de Minas Gerais - Belo Horizonte, MG \\ ${ }^{5}$ Universidade Federal de Pelotas - Pelotas, RS \\ ${ }^{6}$ Membro do INCT/CA/UFMT \\ ${ }^{7}$ Bolsista de produtividade do $\mathrm{CNPq}$
}

\begin{abstract}
RESUMO
Estudou-se o efeito de diferentes níveis de metionina+cistina sobre o desempenho de codornas de corte durante a fase inicial (nascimento ao $21^{\circ}$ dia) e fase total de criação (nascimento ao $35^{\circ}$ dia de idade). Foram utilizadas 288 codornas, de ambos os sexos, distribuídas em delineamento inteiramente casualizado. Os tratamentos consistiram de seis níveis de metionina+cistina total $(0,73 ; 0,79 ; 0,85 ; 0,91$; 0,97 e $1,03 \%$ ), quatro repetições e doze aves por unidade experimental. Os parâmetros avaliados foram peso corporal, ganho de peso, consumo e conversão alimentar para fase inicial e total de criação. Observou-se efeito quadrático significativo do nascimento ao $21^{\circ}$ dia de idade para todos os parâmetros avaliados, sendo observado melhor desempenho nas codornas alimentadas com 0,95\% de metionina+cistina para peso corporal e ganho de peso, e $0,94 \%$ para consumo e conversão alimentar. Houve efeito quadrático do nível de metionina+cistina do nascimento ao $35^{\circ}$ dia de idade para peso corporal, ganho de peso e consumo alimentar, com melhores desempenhos nos níveis de 0,93; 0,93 e $0,94 \%$, respectivamente. A exigência de metionina+cistina para máximo ganho de peso na fase inicial é de $0,95 \%$, e para fase total de criação é de $0,93 \%$.
\end{abstract}

Palavras-chave: aminoácido sulfurado, desempenho, exigência nutricional, ganho de peso

\begin{abstract}
The effect of the methionine+cystine level on the performance of European quail during two phases in the growing period (from hatch to 21 days of age and from hatch to 35 days of age) was evaluated in a completely randomized experimental design with six levels of total methionine +cystine $(.73 ; .79 ; .85 ; .91$; .97 and 1.03\%), and four replicates and 12 quails per experimental unit. Body weight, weight gain, feed intake and feed:weight gain ratio were evaluated in both phases. Significant and quadratic effects of methionine+cystine on the performance traits recorded from hatch to 21 days of age were observed. The highest body weight and weight gain and lowest feed intake and feed:weight gain ratio were estimated for quails fed $.95 \%$ and $.94 \%$ diets. Significant and quadratic effects of metionine+cystine on body weight, weight gain and feed intake from hatch to 35 days of age were estimated for quails fed .93\%; .93\%; and $.94 \%$ diets, respectively. Weight gain methioninine+cystine requirement from hatch to 21 days is $.95 \%$, and from hatch to 35 days of age is $.93 \%$.
\end{abstract}

Keywords: amino acid, performance, nutritional requirement, weight gain

Recebido em 5 de abril de 2011

Aceito em 28 de setembro de 2011

*Autor para correspondência (corresponding author)

E-mail: gerusacorrea@ hotmail.com 


\section{INTRODUÇÃO}

Dentre os fatores que incidem sobre o custo de produção de codornas, a alimentação pode representar mais de $70 \%$ do custo total (Freitas et al., 2006). Sendo assim, a determinação das exigências nutricionais é de grande importância para todas as espécies avícolas, uma vez que o fornecimento de níveis adequados dos nutrientes é o principal fator que determina se as aves vão expressar todo o seu potencial genético (Corrêa et al., 2007b).

Neste contexto, estudos em nutrição de codornas de corte tornam-se cada vez mais importantes, pois se têm utilizado tabelas de exigências nutricionais de outros países, como no caso das tabelas do NRC (Nutrient..., 1994), ou ainda extrapolações dos valores nutricionais para frangos de corte ou codornas de postura, e essas informações podem não ser ideais para o desenvolvimento e o desempenho adequados desta espécie (Corrêa et al., 2006).

Outro fator importante é que as recomendações realizadas pelo NRC (Nutrient..., 1994) correspondem a exigências de codornas japonesas, as quais apresentam características diferentes das codornas europeias, pois as codornas japonesas demonstram ter maior aptidão para postura, o que pode determinar exigências nutricionais diferentes (Corrêa et al., 2007b).

Atualmente, a utilização de aminoácidos sintéticos permite a formulação de dietas com teores reduzidos de proteína bruta, porém sem que ocorra deficiência nem excesso de aminoácidos essenciais.

Dentre os aminoácidos essenciais, a metionina se destaca, pois é o primeiro limitante para aves. Além disso, a metionina e a cistina são consideradas aminoácidos fisiologicamente essenciais para mantença, crescimento e para o desenvolvimento das penas (Pinto et al., 2003).

No organismo, em condições normais, a metionina pode ser catabolizada e convertida em cistina, porém esta conversão não é reversível, pois a cistina não pode ser convertida em metionina, por isso torna-se necessário determinar os níveis adequados destes aminoácidos, atendendo, assim, a exigência para esta inter-relação.

Avaliando a exigência de metionina+cistina total para codornas de corte EV1 em crescimento, Corrêa et al. (2006) encontraram maior ganho de peso quando utilizados os níveis de $0,95 \%$ na fase inicial (sete a 21 dias) e $0,73 \%$ na fase final de criação (22 a 42 dias de idade).

Em outro trabalho, Corrêa et al. (2010), avaliando níveis de 0,73 a $1,03 \%$ de metionina+cistina para codornas de corte EV2 do sétimo ao $21^{\circ}$ dia de idade, observaram aumento no peso corporal e ganho de peso das codornas alimentadas com dietas contendo $0,95 \%$ e $1,03 \%$ de metionina+cistina total para fase inicial (sétimo ao $21^{\circ}$ dia) e total de criação (sétimo ao $42^{\circ}$ dia de idade).

Entretanto, ainda ocorrem controvérsias entre os resultados de pesquisa existentes referente à exigência de metionina+cistina para codornas, motivo esse que impulsionou a realização da pesquisa para estabelecer a exigência de metionina + cistina para codornas de corte do grupo genético EV1, além de não haver trabalhos relacionados à exigência de metionina+cistina em codornas de corte a partir do nascimento ao $35^{\circ}$ dia de idade.

\section{MATERIAL E MÉTODOS}

Foram utilizadas 288 codornas de corte da linhagem EV1 de ambos os sexos, do nascimento ao $21^{\circ}$ dia e do nascimento ao $35^{\circ}$ dia de idade, com peso médio inicial de $9,16 \mathrm{~g}$, as quais foram alojadas em baterias de arame galvanizado com dimensões de $0,82 \mathrm{~m}$ de largura $\mathrm{x} 0,41 \mathrm{~m}$ de profundidade $\mathrm{x} 0,27 \mathrm{~m}$ de altura por unidade experimental, equipadas com bebedouro copo e comedouro tipo calha.

Durante a fase inicial das codornas, foi realizado aquecimento com lâmpadas incandescentes de $100 \mathrm{~W}$ atts na primeira semana e de 60Watts na segunda semana; durante toda a fase experimental, foi adotado o programa de luz de 24 horas.

O experimento foi conduzido em delineamento inteiramente ao acaso, com seis níveis de metionina+cistina total $(0,73 ; 0,79 ; 0,85 ; 0,91$; 
0,97 e $1,03 \%$ ), quatro repetições e 12 aves por unidade experimental.

As dietas foram formuladas com base nas informações nutricionais de composições dos ingredientes apresentadas por Rostagno et al. (2005) e, para atender as exigências nutricionais das codornas, utilizou-se o NRC (Nutrient..., 1994), exceto para metionina+cistina (objeto de estudo). A dieta basal (Tab. 1) foi formulada à base de milho e farelo de soja, contendo $23,89 \%$ de proteína bruta (PB) e $2900 \mathrm{kcal}$ de EM/kg de dieta, a qual foi suplementada com cinco níveis de DL-metionina (99\%), em substituição ao amido de milho, o que corresponde aos níveis de 0,73 (dieta basal sem suplementação); 0,79; 0,85; 0,$91 ; 0,97$ e $1,03 \%$ de metionina+cistina total, permanecendo as dietas isocalóricas e isoproteicas. As dietas e a água foram fornecidas à vontade.

Tabela 1. Composição percentual e calculada da dieta basal

\begin{tabular}{|c|c|}
\hline Ingredientes & $\%$ \\
\hline Milho & 53,469 \\
\hline Farelo de soja & 41,954 \\
\hline Calcário & 1,072 \\
\hline Óleo de soja & 1,016 \\
\hline Fosfato bicálcico & 0,960 \\
\hline Amido & 0,500 \\
\hline Suplemento mineral e vitamínico ${ }^{1}$ & 0,500 \\
\hline Sal comum & 0,265 \\
\hline L-treonina & 0,265 \\
\hline Total & 100,00 \\
\hline \multicolumn{2}{|l|}{ Composição calculada } \\
\hline Proteína bruta $(\%)$ & 23,886 \\
\hline Energia metabolizável (kcal/kg) & 2.900 \\
\hline Cálcio (\%) & 0,800 \\
\hline Fósforo disponível (\%) & 0,300 \\
\hline Sódio $(\%)$ & 0,150 \\
\hline \multicolumn{2}{|l|}{ Aminoácidos totais } \\
\hline Lisina $(\%)$ & 1,300 \\
\hline Metionina + cistina $(\%)$ & 0,731 \\
\hline Triptofano (\%) & 0,305 \\
\hline Metionina (\%) & 0,464 \\
\hline Arginina $(\%)$ & 1,612 \\
\hline Isoleucina $(\%)$ & 1,040 \\
\hline Valina $(\%)$ & 1,107 \\
\hline
\end{tabular}

Para avaliação do desempenho, foram registrados, para cada unidade experimental, peso corporal $(\mathrm{g})$, ganho de peso $(\mathrm{g})$, consumo alimentar $(\mathrm{g})$ e conversão alimentar ( $\mathrm{g}$ de ração/g de peso) do nascimento ao $21^{\circ}$ dia e do nascimento ao $35^{\circ}$ dia de idade.

Para controle do consumo alimentar, as rações de cada repetição, em cada tratamento, foram acondicionadas em sacos plásticos de um quilograma, e estes, por sua vez, acondicionados em baldes plásticos identificados. Ao final de cada período, as sobras de ração do comedouro de cada unidade experimental foram pesadas e, por diferença entre a ração fornecida e as sobras, determinou-se o consumo por período (g/ave). A conversão alimentar por ave foi calculada dividindo-se o consumo de ração/ave pelo ganho de peso/ave de cada unidade experimental e em cada período do experimento.

As análises dos dados foram realizadas por meio do programa SAEG (Sistema..., 2009). Os efeitos dos níveis de metionina+cistina foram calculados 
por análise de regressão, ao se desdobrarem os graus de liberdade dos fatores em seus componentes lineares e quadráticos para escolha do modelo de regressão que melhor descrevesse as observações.

\section{RESULTADOS E DISCUSSÃO}

Os níveis de metionina+cistina da dieta influíram de forma quadrática $(\mathrm{P}<0,05)$ no peso corporal, ganho de peso, consumo e conversão alimentar das codornas do nascimento ao $21^{\circ}$ dia de idade (Tab. 2), de acordo com as respectivas equações de regressão $\hat{Y}_{i}=-1275,58+3024,97 X_{i}$ -
$1597,27 X_{i}^{2}, \quad \hat{Y}_{i}=-1282,65+3020,13 X_{i}-$ $1594,50 X_{i}^{2}, \quad \hat{Y}_{i}=-2031,60+4936,5 X_{i} \quad$ $2612 X_{i}^{2}$ e $\hat{Y}_{i}=11,88-20,96 X_{i}+11,12 X_{i}^{2}$. Observou-se que o peso corporal e o ganho de peso foram aumentados conforme o aumento dos níveis de metionina+cistina até o nível estimado de $0,95 \%$, e o consumo alimentar aumentou até o nível estimado de $0,94 \%$ de metionina+cistina total. A conversão alimentar diminuiu até o nível de $0,94 \%$ de metionina+cistina total, nível no qual as codornas apresentaram melhor eficiência na conversão alimentar.

Tabela 2. Peso corporal (g), ganho de peso (g), consumo alimentar (g) e conversão alimentar (g/g) das codornas de corte EV1 do nascimento ao $21^{\circ}$ dia de idade, segundo o nível de metionina + cistina da dieta

\begin{tabular}{ccccc} 
Nível de metionina & $\begin{array}{c}\text { Peso corporal } \\
(\mathrm{g})\end{array}$ & $\begin{array}{c}\text { Ganho de peso } \\
(\mathrm{g})\end{array}$ & $\begin{array}{c}\text { Consumo alimentar } \\
(\mathrm{g})\end{array}$ & $\begin{array}{c}\text { Conversão alimentar } \\
(\mathrm{g} / \mathrm{g})\end{array}$ \\
\hline 0,73 & 74,65 & 65,50 & 168,62 & 2,56 \\
0,79 & 129,31 & 120,18 & 259,55 & 2,16 \\
0,85 & 142,60 & 133,43 & 276,33 & 2,07 \\
0,91 & 147,56 & 138,33 & 287,06 & 2,08 \\
0,97 & 152,60 & 143,47 & 295,11 & 2,05 \\
1,03 & 149,46 & 140,35 & 287,71 & 2,04 \\
\hline CV & 5,26 & 5,64 & 8,12 & $* 92$ \\
\hline Significância & $*$ & $*$ & $*$ & Ponto de melhor \\
& Equação de regressão & & 0,95 \\
\hline Peso corporal & $\hat{Y}_{i}=-1275,58+3024,97 X_{i}-1597,27$ & $X_{i}^{2}\left(\mathrm{R}^{2}=0,94\right)$ & 0,95 \\
Ganho de peso & $\hat{Y}_{i}=-1282,65+3020,13 X_{i}-1594,50 X_{i}^{2}\left(\mathrm{R}^{2}=0,94\right)$ & 0,94 \\
Consumo alimentar & $\hat{Y}_{i}=-2031,60+4936,5 X_{i}-2612 X_{i}^{2}$ & $\left(\mathrm{R}^{2}=0,93\right)$ & 0,94 \\
Conversão & $\hat{Y}_{i}=11,88-20,96 X_{i}+11,12 X_{i}^{2}$ & $\left(\mathrm{R}^{2}=0,89\right)$ & \\
alimentar & &
\end{tabular}

* = Significativo.

Observou-se que o nível de metionina + cistina total para melhor resposta de peso corporal e ganho de peso deste estudo encontrou-se acima do recomendado por Svacha et al. (1970), que estabeleceram o nível de $0,73 \%$, e acima também do preconizado pelo NRC (Nutrient..., 1994), que corresponde a $0,75 \%$ de metionina + cistina. Pinto et al. (2003) sugeriram o nível de 0,86\% em dietas para codornas japonesas em fase de crescimento.

Entretanto, essa maior exigência em metionina + cistina observada no presente estudo, quando comparada às exigências encontradas pelos autores supracitados, é explicada, pois as codornas de corte apresentam maiores pesos e taxa de crescimento quando comparadas às codornas japonesas, necessitando de maior quantidade de aminoácidos para deposição proteica durante a fase inicial de crescimento.

Resultados semelhantes foram observados por Torres et al. (2005) e Corrêa et al. (2006), os quais encontraram aumentos no peso e ganho de peso de codornas de corte criadas do sétimo ao $21^{\circ}$ dia de idade, quando alimentadas com dietas contendo $0,95 \%$ de metionina + cistina. 
Resultados diferentes foram relatados por Corrêa et al. (2005a), que verificaram por meio da regressão linear que codornas de corte durante a fase inicial (sétimo ao $21^{\circ}$ dia de idade) alimentadas com dietas contendo $1,03 \%$ de metionina + cistina apresentaram maior ganho de peso.

A influência dos níveis abaixo ou acima da exigência de metionina + cistina sobre a conversão alimentar indica que o aumento dos níveis possivelmente foi suficiente para promover um imbalanço aminoacídico, resultando na alteração do perfil plasmático nas aves as quais ativam os mecanismos reguladores do apetite, que fazem com que haja aumento na ingestão de alimentos, como descrito por Harper et al. (1970).

Quanto ao consumo alimentar até o nível de $0,94 \%$ de metionina + cistina, as codornas aumentaram o consumo, possivelmente na tentativa de suprir a necessidade de metionina + cistina, e após a exigência ter sido atendida, as codornas reduziram o consumo, talvez pelo excesso de metionina ter se tornado tóxico para a ave.

Stringhini et al. (1998), avaliando níveis de metionina na dieta $(0,45$ e $0,50 \%)$, não observaram efeito significativo sobre o consumo alimentar de codornas japonesas. Pinto et al.
(2003) verificaram efeito significativo dos níveis de metionina + cistina digestível $(0,55$ a $0,86 \%)$ sobre consumo alimentar, sugerindo nível ótimo de $0,69 \%$, porém não observaram efeito significativo para conversão alimentar de codornas japonesas em crescimento. Enquanto Corrêa et al. (2005a), testando níveis de 0,73 a $1,03 \%$ de metionina + cistina total para conversão alimentar, verificaram efeito linear decrescente, observando melhor conversão alimentar no nível $1,03 \%$ de metionina + cistina para codornas europeias.

Houve efeito quadrático $(\mathrm{P}<0,05)$ para peso corporal, ganho de peso e consumo alimentar das codornas do nascimento ao $35^{\circ}$ dia de idade (Tab. 3), de acordo com as respectivas equações de regressão $\hat{Y}_{i}=-1413,01+3618,87 X_{i}$ $1952,07 X_{i}^{2}, \hat{Y}_{i}=-1420,08+3614,02 X_{i}-$ $1949,30 X_{i}^{2}$ e $\hat{Y}_{i}=-3225,58+8341,84 X_{i}$ $4429,40 X_{i}^{2}$, com máximo desempenho nos níveis de $0,93 \%$ para peso corporal e ganho de peso, e para consumo alimentar $0,94 \%$ de metionina + cistina total.

Os níveis de metionina + cistina não influenciaram $(\mathrm{P}>0,05)$ a conversão alimentar das codornas do nascimento ao $35^{\circ}$ dia de idade.

Tabela 3. Peso corporal (g), ganho de peso (g), consumo alimentar (g) e conversão alimentar (g/g) das codornas de corte EV1 do nascimento ao $35^{\circ}$ dia de idade, segundo o nível de metionina + cistina da dieta

\begin{tabular}{ccccc} 
Nível de metionina & $\begin{array}{c}\text { Peso corporal } \\
(\mathrm{g})\end{array}$ & $\begin{array}{c}\text { Ganho de peso } \\
(\mathrm{g})\end{array}$ & $\begin{array}{c}\text { Consumo alimentar } \\
(\mathrm{g})\end{array}$ & $\begin{array}{c}\text { Conversão alimentar } \\
(\mathrm{g} / \mathrm{g})\end{array}$ \\
\hline 0,73 & 174,68 & 165,52 & 480,91 & 2,90 \\
0,79 & 251,81 & 242,67 & 641,58 & 2,66 \\
0,85 & 254,22 & 245,05 & 661,28 & 2,70 \\
0,91 & 252,12 & 242,88 & 682,22 & 2,82 \\
0,97 & 251,33 & 242,20 & 680,51 & 2,81 \\
1,03 & 252,32 & 243,21 & 682,12 & 2,80 \\
\hline $\mathrm{CV}$ & 6,05 & 6,29 & 5,90 \\
\hline Significância & $*$ & $*$ & ns \\
\hline \multicolumn{2}{c}{ Equação de regressão } & desempenho de melhor \\
\hline Peso corporal & $\hat{Y}_{i}=-1413,01+3618,87 X_{i}-1952,07 X_{i}^{2}\left(\mathrm{R}^{2}=0,79\right)$ & 0,93 \\
Ganho de peso & $\hat{Y}_{i}=-1420,08+3614,02 X_{i}-1949,30 X_{i}^{2}\left(\mathrm{R}^{2}=0,79\right)$ & 0,93 \\
Consumo & $\hat{Y}_{i}=-3225,58+8341,84 X_{i}-4429,40 X_{i}^{2}\left(\mathrm{R}^{2}=0,91\right)$ & 0,94 \\
alimentar &
\end{tabular}

* = Significativo; ns = Não significativo. 
Resultados semelhantes foram observados por Ferreira et al. (2010), que, ao avaliarem o desempenho de codornas de corte criadas do nascimento ao $35^{\circ}$ dia de idade, também observaram efeito quadrático significativo para os níveis de metionina + cistina testados sobre peso final, ganho de peso e consumo alimentar, em que o máximo ganho de peso foi obtido com o nível $0,95 \%$.

Corrêa et al. (2005b; 2007a) observaram menor exigência de proteína com o aumento da idade, inferindo que tal fato ocorre em função da diminuição do ganho de peso com o aumento da idade da codorna. Isso pode ser relacionado à diminuição da necessidade em aminoácidos pelas codornas com o avanço da idade, fato observado neste estudo para o requerimento de metionina + cistina.

Entretanto, Pinto et al. (2003), trabalhando com níveis de 0,55 a $0,86 \%$ de metionina + cistina digestível na dieta, verificaram efeito linear positivo dos níveis testados sobre o peso no $42^{\circ}$ dia e ganho de peso do sétimo ao $42^{\circ}$ dia de idade, para codornas japonesas em crescimento. Corrêa et al. (2010), trabalhando com os mesmos níveis testados no presente estudo $(0,73 ; 0,79$; 0,$85 ; 0,91 ; 0,97$ e $1,03 \%$ de metionina + cistina), também observaram efeito linear positivo dos níveis testados sobre o ganho de peso e o consumo alimentar de codornas de corte criadas do sétimo ao $42^{\circ}$ dia de idade.

Para conversão alimentar, não houve efeito significativo dos níveis de metionina + cistina total testados. Trabalhos realizados por Corrêa et al. (2006; 2010) também não observaram diferenças significativas dos níveis de metionina + cistina para a conversão alimentar de codornas de corte do sétimo ao $42^{\circ}$ dia de idade.

\section{CONCLUSÕES}

A exigência de metionina + cistina total para máximo ganho de peso de codornas de corte EV1 na fase inicial é de $0,95 \%$, e para fase total de criação é de $0,93 \%$, o que corresponde às relações de metionina + cistina: lisina de 0,73 e 0,71 , respectivamente.

\section{REFERÊNCIAS}

CORRÊA, G.S.S.; SILVA, M.A.; CORRÊA, A.B. et al. Níveis de metionina + cistina para híbridos EV1 de codornas europeias no período de crescimento. In: REUNIÃO ANUAL DA SOCIEDADE BRASILEIRA DE ZOOTECNIA, 42., 2005. Goiânia. Anais... Goiânia, GO: SBZ, $2005 \mathrm{a}$.

CORRÊA, G.S.S.; SILVA, M.A.; FONTES, D.O. et al. Efeito de níveis de proteína e energia sobre o rendimento de carcaça de codornas europeias. Arq. Bras. Med. Vet. Zootec., v.57, p.266-271, 2005b.

CORRÊA, G.S.S.; SILVA, M.A.; CORRÊA, A.B. et al. Exigência de metionina + cistina total para codornas de corte em crescimento. Arq. Bras. Med. Vet. Zootec., v.58, p.414-420, 2006.

CORRÊA, G.S.S.; SILVA, M.A.; CORRÊA, A.B. et al. Exigência de proteína bruta e energia metabolizável para codornas de corte EV1. Arq. Bras. Med. Vet. Zootec., v.59, p.797-804, 2007a.

CORRÊA, G.S.S.; SILVA, M.A.; CORRÊA, A.B. et al. Exigências em proteína bruta para codornas de corte EV1 em crescimento. Arq. Bras. Med. Vet. Zootec., v.59, p.1278-1286, 2007b.

CORRÊA, G.S.S.; SILVA, M.A.; CORRÊA, A.B. et al. Níveis de metionina + cistina para características de desempenho e carcaça em codornas de corte EV2. Arq. Bras. Med. Vet. Zootec., v.62, p.940-947, 2010.

FERREIRA, F.; CORRÊA, G.S.S.; SILVA, M.A. et al. Exigência de metionina+cistina total para codornas de corte EV2 do nascimento ao $35^{\circ}$ dia de idade. In: CONGRESSO BRASILEIRO DE ZOOTECNIA, 20., 2010, Palmas, TO. Anais... Palmas: ZBZ, 2010.

FREITAS, A.C.; FUENTES, M.F.F.; FREITAS, E.R. et al. Níveis de proteína bruta e energia metabolizável na ração para codornas de corte. Rev. Bras. Zootec., v.35, p.1705-1710, 2006.

HARPER, A.E; BENEVENGA, N.J.; WOHLHUETER, R.M. Effects of ingestion of disproportionate amounts of amino acids. Physiol. Rev., v.50, p.428-558, 1970.

NUTRIENT requeriments of poultry. 9.ed., Washington: National Academy of Sciences, 1994, 155p. 
PINTO, R.; FERREIRA, A.S.; DONZELE, J.L. et al. Exigência de metionina mais cistina para codornas japonesas em crescimento. Rev. Bras. Zootec., v.32, p.1174-1181, 2003.

ROSTAGNO, H.S.; ALBINO, L.F.T.; DONZELE, J.L. et al. Tabelas brasileiras para aves e suínos: composição de alimentos $\mathrm{e}$ exigências nutricionais. Viçosa: UFV, 2005. $183 \mathrm{p}$.

STRINGHINI, J.H.; MOGYCA, N.S.; CAFÉ, M.B. et al. Níveis de energia metabolizável e de metionina em rações para codornas (Coturnix coturnix japonica) em postura. Acta Sci., v.20, p.407-411, 1998.
SVACHA, A.; WEBER, C.W.; REID, B.L. Lysine, methionine and glycine requirements of japanese quail to five weeks of age. Poul. Sci., v.49, p.54-59, 1970.

TORRES, R.A.; CORRÊA, G.S.S.; SILVA, M.A. et al. Desempenho de codornas EV2 para corte alimentadas com dietas com diferentes níveis de metionina + cistina durante a fase inicial. In: REUNIÃO ANUAL DA SOCIEDADE BRASILEIRA DE ZOOTECNIA, 42., 2005. Goiânia. Anais... Goiânia, GO:SBZ, 2005.

SISTEMA para análise estatística e genéticaSAEG, Viçosa, MG: Fundação Arthur Bernardes, 2009. 